Short Communication

\title{
Experimental Study on Removal of Emulsified Oil by Electrocoagulation with a Rotating Container
}

\author{
Jianwu Liu ${ }^{1}$, Wenming Jiang ${ }^{1,2, *}$, Guangqing Wang ${ }^{1}$, Lei Zhang ${ }^{1}$, Yimei Chen ${ }^{2}$, Ran Xin ${ }^{3}$ \\ ${ }^{1}$ Shandong Provincial Key Laboratory of Oilfield Produced Water Treatment and Environmental \\ Pollution Control (Sinopec Petroleum Engineering Corporation), Dongying 257061, China; \\ ${ }^{2}$ College of Pipeline and Civil Engineering, China University of Petroleum, Qingdao 266580, China; \\ ${ }^{3}$ Chemical and Material Engineering, University of Alberta, Edmonton T6G2E1, Canada) \\ *E-mail: jiangwenming@upc.edu.cn
}

doi: $10.20964 / 2019.06 .47$

Received: 6 February 2019 / Accepted: 18 March 2019 / Published: 10 May 2019

\begin{abstract}
Electrocoagulation (EC) was proved to be highly effective to remove the oil from oily sewage in an oilfield. However, much work still needs to be done to improve the oil removal performance and to reduce the energy consumption of the EC device. In this text, a rotating container method was employed for the purpose of strengthening the mass transfer process in the EC device. Firstly, the effect of different rotation rates and APEs on the oil removal process was determined, showing that the rotation of the container decreases the effect of EC on oil removal. Then, the effect of the current density on oil removal was investigated, showing that the oil removal efficiency rises with increasing current density. Lastly, the effect of the rotation rate on the appearance time of flotation was investigated, showing that the rotation of the container slows down the formation of floating floc, resulting in a lower oil removal efficiency.
\end{abstract}

Keywords: Electrocoagulation; oily sewage; oil removal efficiency; rotation container.

\section{$\underline{\text { FULL TEXT }}$}

(C) 2019 The Authors. Published by ESG (www.electrochemsci.org). This article is an open access article distributed under the terms and conditions of the Creative Commons Attribution license (http://creativecommons.org/licenses/by/4.0/). 